\title{
Melt Rheology of Renewable Polymers and of New Materials Based on them as Tool in Controlling the 3D/4D Printability
}

\author{
DOINA DIMONIE, NICOLETA DRAGOMIR*
}

${ }^{1}$ INCDCP -ICECHIM Bucharest, 202 Spl. Independentei, 060021, Bucharest, Romania

\begin{abstract}
The article presents results regarding the use of the melt flow index method (MFIM) in estimating the rheological properties of polylactic acid (PLA) and PLA-based materials, as tool in the selection of the operating conditions at their shaping into filaments and for $3 D$ printing with thus obtained filaments. Based on the MFIM, the molecular weight of various PLA grade commonly used in melt processing techniques, including printing, were qualitatively compared. It was found that PLA for printing has the lowest molecular weight as compared with the PLA melt processed through injection, extrusion, thermoforming. It has been also shown that the MFIM can be used to verify the efficiency of drying, pre-treatment always needed to be done, before filaments obtaining and/or printing, especially in case of renewable polyesters. By simulating the printing at the indexer, via depositing successive layers, one over the other, it was possible to estimate the optimal flow conditions that ensure a good adhesion between the deposited layers. The estimation of the condition which ensure the needed adhesion between the deposited layers with the help of the MFIM was verified with good results on a grade of high loaded PLA achieved according to an original formulation.
\end{abstract}

Keywords: renewable, polymers, melt rheology properties, melt flow index method, PLA, filaments, $3 D / 4 D$ printing

\section{Introduction}

It is well known that the subtractive manufacturing technique uses blocks of material from which the unnecessary parts are removed until the shape of the desired item is obtained. Unlike this technique, in the $3 \mathrm{D}$ procedures, the three-dimensional object is acquired under the computer's control, by successive deposition of layers of approx. $0.15 \mathrm{~mm}$ thickness, one over the other, until the desired shape is achieved. That is why this technique is also called "additive /cumulative manufacturing" [1,2] or 3D printing [3]. Evident the 3D printing does not require molds because the items results after the material is added in successive layers.

The 3D printing presents the advantage of obtaining complex items in shapes, with properties much better tailored to the market requirements. Although the concept is very old since it seems to be used to construct the Egyptian pyramids, it was imposed as manufacturing process, in the late 1980s and early 90s. Nowadays the 3D printing is considered a revolutionary process which can become the third technical revolution of the mankind.

The smart polymeric materials represent a latest materials generation designed for high-performance applications and are materials which respond to post-print action external stimuli, by changing, in time, their physical properties and/or shape, volume, color, swelling ratio etc. [4-8]. Amorphous, semicrystalline polymers or polymers with two phase transitions can be used to get intelligent material [9]. Smart materials are the ideal candidates for 4D printing because, after printing, the obtained objects are activated, as mentioned, in time, by various stimuli, having time as the fourth dimension [10-13]. The 3D printers, considered as real industrial robots, can be equally used, both in 3D and 4D printing [14,15].

As the authors' research regards the development of new polymeric materials designed for 3D and 4D printing-fused deposition modeling (FDM) method, it was necessary to find a way to qualitatively estimate the melt flow of the used polymers and /or of the new achieved polymeric compounds.

*email: lauranicoleta.dragomir@gmail.com 
The melt flow index method (MFIM) which has as base principle the finding of the quantity of melted material extruded through a die, in a given time, by working in specified conditions [16-18] simulates the flow in elongational field. This method is generally used as preliminary guide for roughly comparing the processing and flow characteristics of different polymers or polymeric materials, to study the elastic behavior of melted polymers and so [19]. The MFIM is also useful in evaluations regarding the quality of the extrudates, diameter's constancy, surface appearance and roughness etc. It gives information about the dependence between the flow conditions and fluidity (MFI), melt resistance to flow (dynamic viscosity), melt density, activation energy of the viscous flow etc.

During the polymeric materials flowing, the so-called instability phenomenon (unstable flow) which affects the quality of the extrudates can occur and therefore, in all situations, it must be avoided [20,21] especially in shaping of polymeric materials as filaments for 3D printing. It must be mentioned also that the filaments must meet requirements regarding their melt viscosity, the constancy of the diameter and ovality, the stretchability before breaking, the volatile formation during 3D printing [22-24].

Due to its structure consisting in rigid blocks placed in an amorphous matrix, PLA is successfully used instead of conventional polymers, in all melt processing techniques including the 3D printing [2528]. PLA is an ideal candidate for achieving smart materials for 4D printing [29-31].

The purpose of the paper was to study the possibility to use the MFIM for estimation the melt rheology characterizing both the shapeability of polymeric materials as filaments and the 3D printability of thus obtained filaments with reaching printed items with good adhesion between the deposited layers. The paper present also the results regarding the usage of this method in estimation the macromolecular features of PLA possible to be used in printing technology and in analysis the efficiency of drying as obligatory stage in 3D printing of PLA and /or of new materials based on PLA.

\section{Materials and methods}

\subsection{Method}

In order to identify the most appropriate PLA grade that can be used in 3D / 4D printing and in subsequent modification researchers for getting new materials for printing technologies, the molecular weights were estimated, qualitatively, based on the rheological properties of the melts for several types of PLAs designed for melt processing into finished product both by classical techniques (injection, extrusion blowing film, thermoforming) and by 3D/4D printing.

For estimation the variation ranges of the working parameters that define the melt compounding, filament formation and 3D printing, and to verify if the formulations do not induce melt flow instability, the melt rheological properties and the characteristics of the extrudates obtained at the indexer have been studied, both for PLA and target filler based PLA, modified accordingly to an original solution [32].

The printability of the studied polymeric materials was estimated considering their capacity to be over-laid, at indexer, in layers which has, in the cold state, good interface adhesion. It has been also verified if the working conditions, estimated at the indexer are proper for shaping of studied materials as filaments and for 3D printing of the achieved filaments.

\subsection{Materials and characterization}

The melt rheological properties were measured with the melt flow index (MFI) method using an DYNISCO 4000 LMI indexer which displayed the following properties: melt flow index (MFI), dynamic viscosity, flow ratio, shear rate, and shear stress. The indexer was equipped with a nozzle having 2.09 ration between height and diameter $(\mathrm{h} / \mathrm{D})$ The measurements were done at four temperatures (from the range of $200-240^{\circ} \mathrm{C}$ ) and four loads (between $2.16 \mathrm{~kg}$ and $10 \mathrm{~kg}$ ) because, in accordance with the experimental statistic, this is the minimum number of experimental points which ensure the relevance of the conclusions on a process or a phenomenon. Each extrudate was cut after $120 \mathrm{~s}$. The measurements were done under the same conditions, respectively the variation of the temperature in the range of 200$240^{\circ} \mathrm{C}$ and the loading of the plastometer with weight between $2.19 \mathrm{~kg}$ and $10 \mathrm{~kg}$. 
If MFI described the polymer fluidity, the dynamic viscosity represents the tangential force per unit required to move, at unit rate, one horizontal plane with respect to the other (Newton's low frictions) [33]. In a simple expression, dynamic viscosity characterizes the melt flow resistance and signifies the internal friction resulting in a melt when one layer of fluid is moving in relationship to other one [34].

The shear rate-temperature dependency characterized the nature of the flow ration: unstable when the relationship is linear and, as consequence, the obtained extrudates have sharkskin surface (the magnitude of the defects depending on the extent of the melt flow instability), or stable when the relationship is concave and the extrudates present smooth appearance [35].

The laboratory shapeability as filaments of new compounds has been verified on a Brabender extruder by working in common conditions $\left(180-200^{\circ} \mathrm{C}, 50 \mathrm{rpm}\right)$. The selected compounds were scaled up on a line with the following devices: $50 \mathrm{~kg} / \mathrm{h}$ twin screw extruder $(\varphi=35.6 \mathrm{~mm}, \mathrm{~L} / \mathrm{D}=48$, compression ratio $=2.9$, heating zones $=9$, degassing zone and screen changer), water cooling bath, air dryer, granulator. The obtained granules were extruded into filaments for printing technology of 1.85 $+/-0.05 \mathrm{~mm}$ diameter on a Gotffert mono screw extruder $\left(170-180^{\circ} \mathrm{C}, 150 \mathrm{rpm}\right)$, with line for filaments drawing, calibration, cooling and rolling $\left(90^{\circ} \mathrm{C}, 20^{\circ} \mathrm{C}, 80 \mathrm{rpm}\right)$.

The 3D printability of the new filaments was tested on a UP! Plus 2 3D Printer, Z SPOT MEDIA SRL, $10-100 \mathrm{~cm}^{3} / \mathrm{h}$ printing speed, 140x140x135 mm printing size, self-generated model support, 0.20$0.40 \mathrm{~mm}$ or $0.15-0.35 \mathrm{~mm}$ layer thickness, STL file input format.

The following PLA grade have been investigated: PLA 850 (Natura Works, Ingeo 3D850, MFI 7-9 g/10 min., density $1.24 \mathrm{~g} / \mathrm{cm}^{3}$, code-PLA 3D/4D printing), PLA D 2003 (1.24 g/ cm ${ }^{3}$ density, $32 \mathrm{~g} / 10$ min. MFI, code -PLA thermoforming), PLA D $3052\left(1.2 / \mathrm{cm}^{3}\right.$ density and $14 \mathrm{~g} / 10 \mathrm{~min}$., code-PLA injection), PLA D 4032 (1.2 g/ $\mathrm{cm}^{3}$ density, $7 \mathrm{~g} / 10 \mathrm{~min}$. MFI, code PLA-blow film extrusion), PLA with target filler-own formulation $\left(18 \mathrm{~g} / 10 \mathrm{~min}\right.$. MFI $195^{\circ} \mathrm{C} / 2.16 \mathrm{~kg}, 1.32 \mathrm{~g} / \mathrm{cm}^{3}$ density). All these PLA type behave optimally at melt processing into finished product, each of them being marketed for the mentioned application.

\section{Results and Discussions}

\subsection{Estimation of the molecular weight of the different PLA grades}

The relationships between the flow conditions and the melt fluidity of some grades of PLA that can be melt processed into finished product by 3D/4D printing, thermoforming, injection and film blowing extrusion are presented in Figure 1.
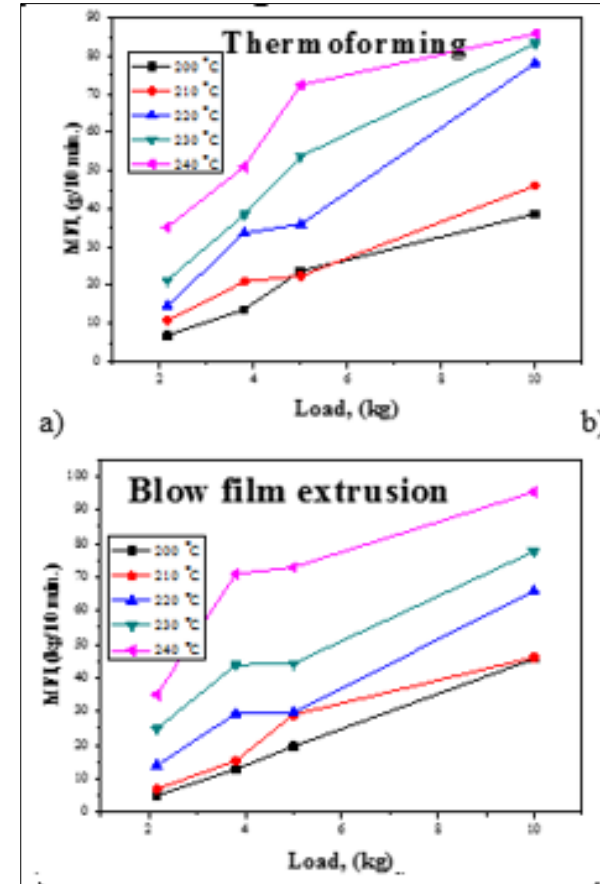

c)
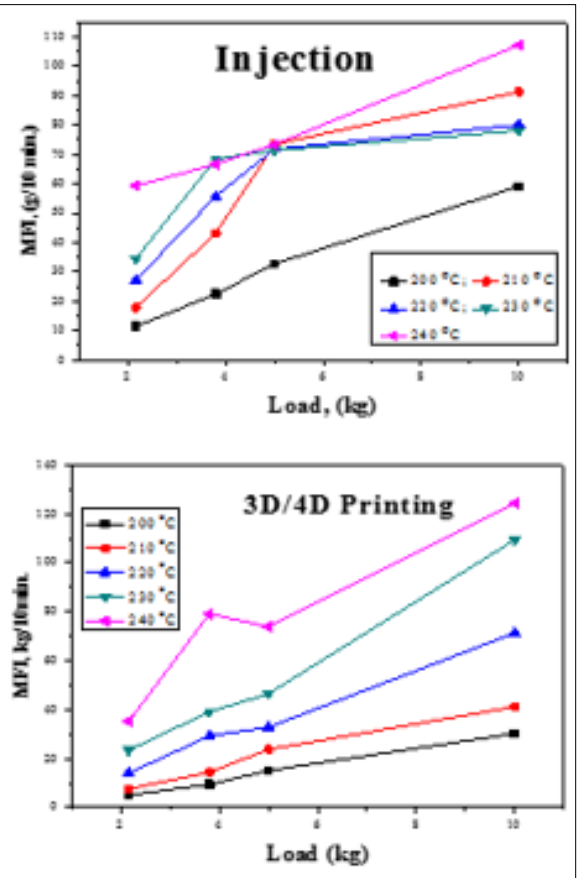

d)

Figure 1. Fluidity variation with flow conditions for various grades of PLA melt processed into finished product by:

(a)-thermoforming;

(b)-injection; (c)-blow film extrusion; (d)-3D / 4D printing 
The dependences fluidity-flowing conditions are linear which suggests a newtonean flow in all situations. However, the fluidity for each flow conditions depends on the PLA grade and is in good agreement with the application.

According to Equation 1, if the MFI has high values than the polymer's molecular weight is low [36]. As it can be seen in Figure 1, the fluidity of the studied PLAs has the lowest value for the grade used for thermoforming, Equation (1):

$$
\frac{1}{M F I}=G M_{w}^{x}
$$

The fluidity is slightly higher both for injection PLA and for the blow extrusion grade, results which indicate that they are polymers with similar, lower molecular weight. The highest fluidity and therefore the lowest molecular weight were registered for the PLA melt processable into finished product by printing techniques.

The found qualitative order of the increasing of the molecular weight for the PLA grades processable in finished product by several melting techniques are described by equation (2):

$$
\mathrm{M}_{\mathrm{w}} 3 \mathrm{D} \text { printing }<\mathrm{M}_{\mathrm{w}} \text { blow film extrusion }<\mathrm{M}_{\mathrm{w}} \text { injection }<\mathrm{M}_{\mathrm{w}} \text { thermoforming }
$$

This order has practical importance in the selection of PLA grade for desired application especially if the information related to the possible melt processing technique are missing. Knowledges related to the molecular weight of PLA that ensure optimal behavior in 3D printing, generally not found. The information regarding the qualitative estimation of molecular weight from the melt rheological data, considering gel permeation chromatography measurements, normally can be confirmed [36].

\subsection{PLA drying before shaping as filaments}

The extrusion behavior of PLA and the relationship between the flowing conditions and the shear rate, and the fluidity (MFI) of non-dry and dry PLA are presented in Figure 2.

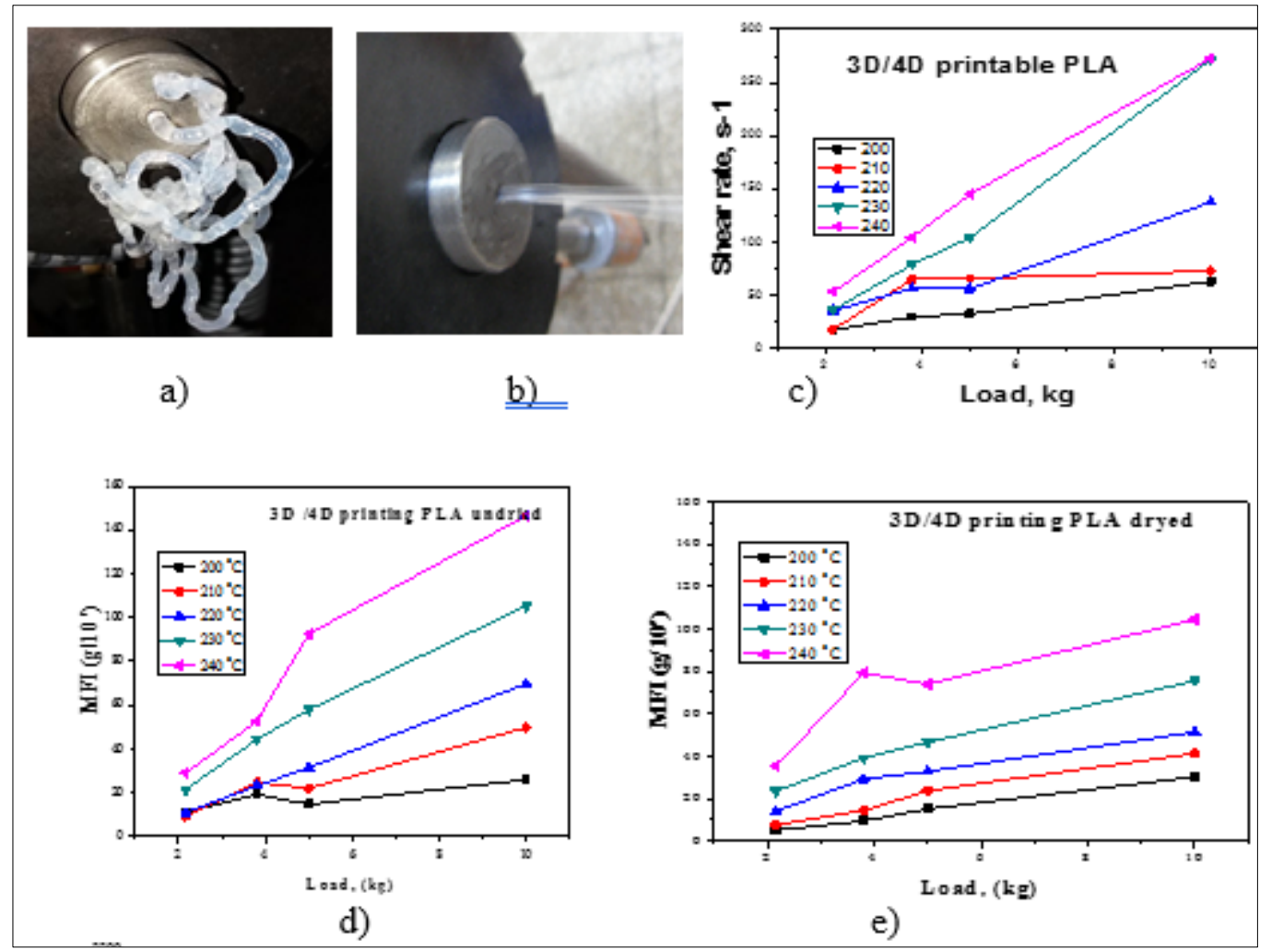




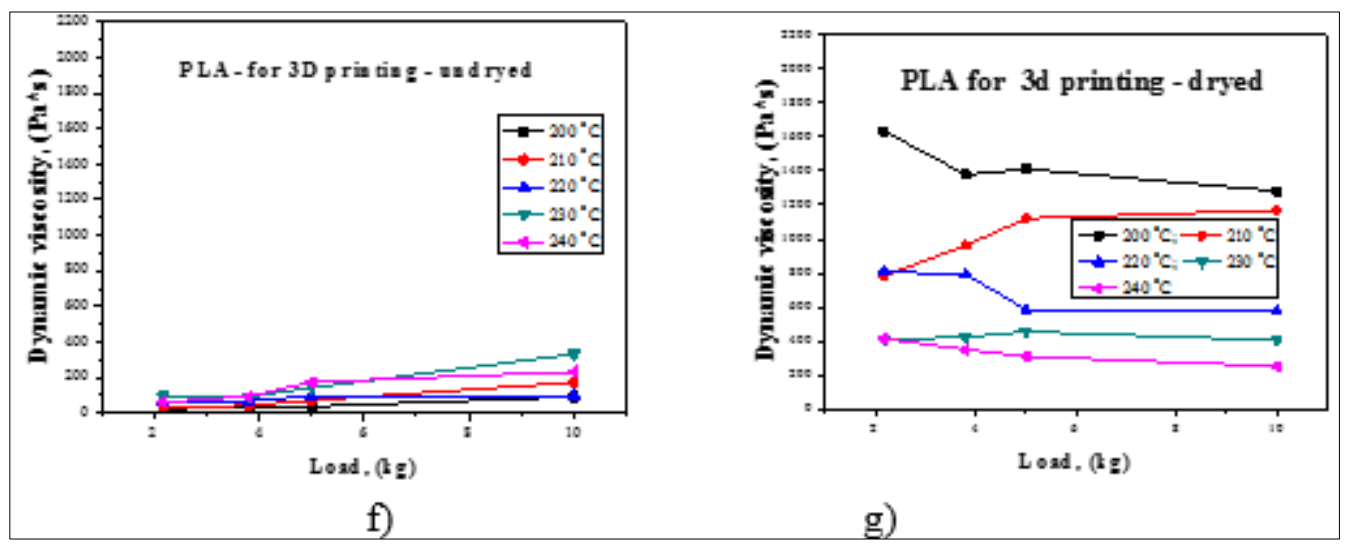

Figure 2. The extrusion behavior (a, b, c), in shear field (Figure c), of non-dry (a) and dry

(b) PLA and the differences between the fluidity (d, e) and dynamic viscosity (f, g) with the flow conditions for non-dry PLA (d, f) and dry PLA (e, g)

PLA cannot be shaped as filament if the polymer was not dried in advance, a necessity demonstrated first of all, by the appearance of the polymer at the exit from the extruder nozzle (Figure $2 \mathrm{~b}$ ) and secondly, by the relationship between the fluidity and the flow conditions for the non-dry PLA (Figure 2d). In the same shear rate variation range (Figure 2a), the PLA fluidity increases, with the temperature, much more for the non-dry polymer (Figure 2d) and less for the dry one (Figure 2e). As shown the results obtained, the dependence of fluidity on the indexer's load is not as marked as in case of the relation between the fluidity and the flow temperature.

An interesting behavior was registered for the variation of the melt resistance to flow with flowing conditions for non-dry PLA (Figure 2f), property that has very small values, almost invariable, for all the studied situations. The melt resistance to flow of dry PLA (Figure 2g) varies with the flow conditions, in a completely different way, this property registering main increases with the temperature and almost irrelevant changes dependent on the indexer's load. If the operating temperature increases from $200^{\circ} \mathrm{C}$ to $240^{\circ} \mathrm{C}$ then the melt resistance to flow decreases from approx. $1600 \mathrm{~Pa}^{*} \mathrm{~s}$ at approx. $300 \mathrm{~Pa}^{*} \mathrm{~s}$, namely closed to 5 times.

Depending on the melt resistance to flow values it can be stated that if the material has not been dried then the flow is almost impossible to be perform, as it was experimentally observed, first of all because the melt is not sensitive to changing of the flow conditions (Figure 2e). In this situation, regardless the flow parameters values, the melt resistance to flow has extremely low values, up to max.200 $\mathrm{Pa}^{*} \mathrm{~s}$ at $\mathrm{T}$ of $240^{\circ} \mathrm{C}$ and maximum load of $10 \mathrm{~kg}$, conditions in which the macromolecules there are no more long chains.

The origin of the very low dynamic viscosity of non-dry PLA, most likely, must be related to the degradation of polymer under the temperature and residual water influence.

Like many aliphatic polyesters, PLA degrades during melt processing because of temperature and residual moisture, process which finally affects the functional properties. Being a polycondensation polymer, event very small amounts of water generates the de-polycondensation of the PLA macromolecules and thus the decreasing of the molecular weight (Eq.3).

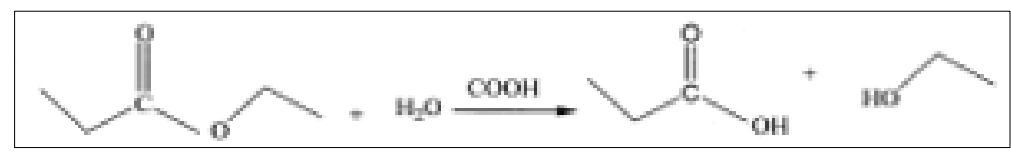

This reaction generates an increase of the melt fluidity, the decrease of the flow resistance to flow and then the loss of functional properties [37-39]. 
If the polymer was dry then the high values of the melt fluidity can be the consequence of the increased kinetic energy of the macromolecules because of the temperature influence, situation in which the functional properties of the polymer does not change.

Practically, the measuring of the dynamic viscosity variation with the flow conditions can be a method of checking the efficiency of PLA and/or of PLA-based materials drying, procedure that must precedes the melt processing, including the 3D/4D printing.

The melt viscosity of PLA is much more stable, if the drying was done up to $250 \mathrm{ppm}$, even $200 \mathrm{ppm}$ (amorphous PLA: $4 \mathrm{~h}$ at $60^{\circ} \mathrm{C}$, crystalline PLA: $4 \mathrm{~h}$ at $80^{\circ} \mathrm{C}$ ). If the residence time in the processing machine is longer and / or the melting temperature is higher than the residual water content after drying must be less than 50 ppm [40].

\subsection{The estimation of the conditions for PLA shaping as filaments and for 3D printing}

The preliminary selection of the processing conditions for shaping of PLA as filament was also made with the help of a preliminary study of flowing in the extensional field at the indexer, using polymer previously dried till moisture content as in 3.2. As example it was observed that the diameter of the filaments decreases significantly with the increase of the extrusion temperature (Table 1).

Table 1. Dependence of the filament diameter on the melt temperature

\begin{tabular}{|c|c|c|c|c|}
\hline \multirow{2}{*}{$\begin{array}{c}\text { Filament diameter, } \mathrm{mm} \\
\text { Temperature, }{ }^{0} \mathrm{C}\end{array}$} & \multicolumn{4}{|c|}{ Temperature, ${ }^{\circ} \mathrm{C}$} \\
\cline { 2 - 5 } & 180 & 190 & 200 & 210 \\
\hline Filament diameter, $\mathrm{mm}$ & 1.45 & 1.41 & 1.1 & 06 \\
\hline
\end{tabular}

Furthermore, by following the appearance of the extrudates, the surface quality and their color, it was possible to identify the range of the extrusion parameters variation which ensure the obtaining white extrudates with smooth surface and constant diamer.

The working conditions in which the extrudates meet the requirements for 3D printing were selected as primary information for the shaping of PLA as filaments (Figure 3).

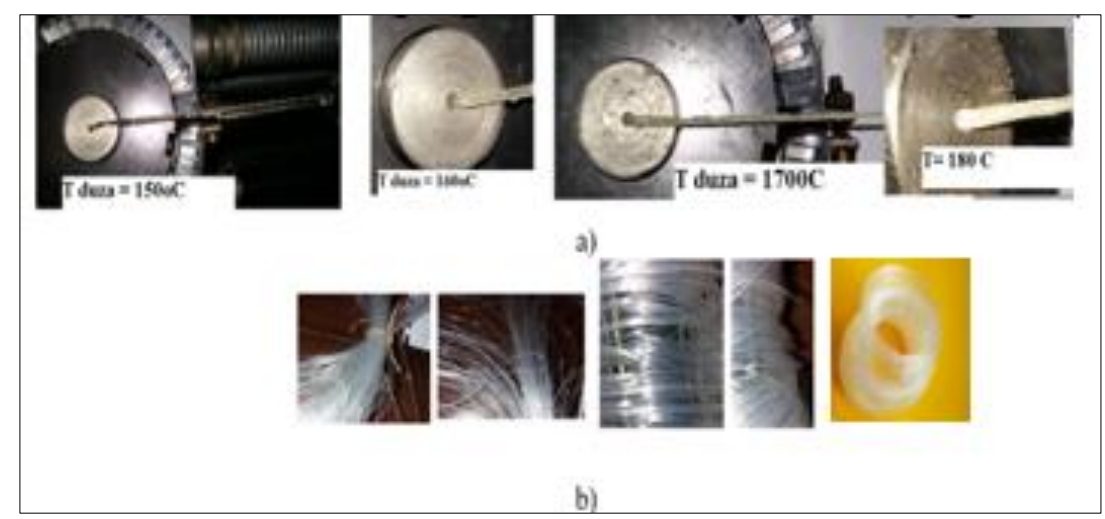

Figure 3 The appearance of the filaments obtained by extrusion at temperatures from the range selected at the indexer (a)- filament at the exit of the extruder nozzle; (b)-bulk filaments

These experiments led to the conclusion that the optimal extrusion temperatures which allowed the achieving of filaments with constant diameter, required ovality and smooth surface (Figure 4) is placed in the range of interest selected at indexer. 


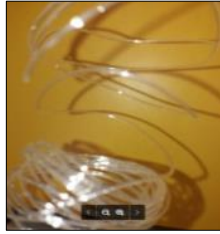

a)

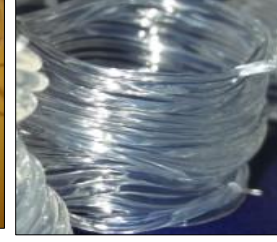

b)

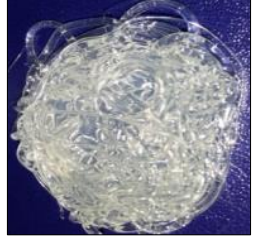

c)

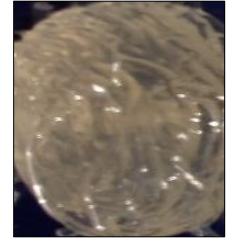

d)

Figure 4. The dependence of the deposition of the extruded melted PLA at indexer on the extrusion temperature (a) $-200^{\circ} \mathrm{C}$; (b) $-220^{\circ} \mathrm{C}$; (c) $-230^{\circ} \mathrm{C}$; (d) $-240^{\circ} \mathrm{C}$

In a simulation experiment of the 3D printing at indexer which consisted in depositing layer over layer of the melt, it was found that after cooling, the adhesion between deposited layers, depends on the temperature at which the extrudates were layered (Figure 4). After cooling of thus obtained item, it was observed that the layers do not adhere to each other if the deposition temperature was $200^{\circ} \mathrm{C}$ (Figure 4 a). If the temperature was $240^{\circ} \mathrm{C}$, then the material turned rapidly into a yellow (probably because of degradation), compact mass and could not be deposited as layer over layer (Figure 4c, Figure 4d). Laying layer over layer with adhesion, after cooling, between them and obtaining of an item with a well-defined shape was possible only at $210^{\circ} \mathrm{C}$ temperature (Figure $4 \mathrm{~b}$ ).

It was noted that the deposition layer over layer with obtaining of an item with adhesion between layers depends not only on the temperature values but also on the indexer load. The adhesion between the layers is favored by the large load of the indexer $(5 \mathrm{~kg}-10 \mathrm{~kg})$ (Figure 5).

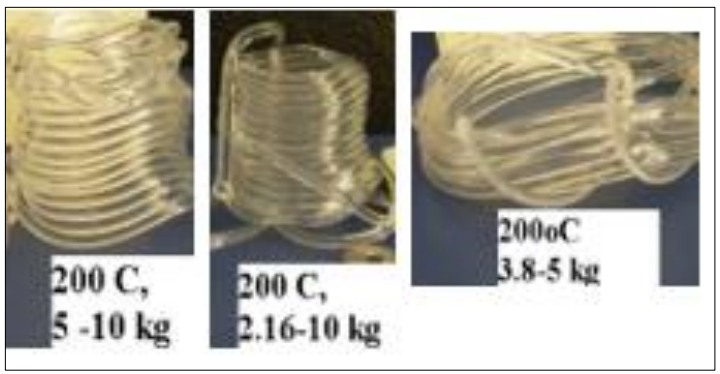

Figure 5. The dependence of the adhesion of the deposited polymer layers on the indexer loading

These results demonstrate that the adhesion between the layers deposited one on top of the other for simulating the 3D printing depends on the melt rheological properties, parameters which must be identified for each type of polymeric material and printed item.

The working conditions selected in the above described experiments were used as an elementary guide for 3D printing. It was possible thus to narrow the range of experiments for identifying the optimal conditions for a successful 3D printing (Figure 6).

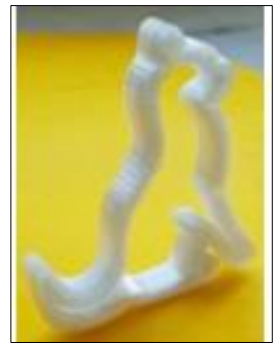

Figure 6. 3D printed items obtained in conditions selected in indexer experiment

The experimental results showed that the same polymeric material, respectively dry PLA, requires different conditions for shaping as filaments and for 3D printing. It was observed that filaments with diameter of $1.85 \mathrm{~mm}+/-0.05 \mathrm{~mm}$ are obtained if the shaping is done at $200^{\circ} \mathrm{C}$ and the $3 \mathrm{D}$ printing succeeds if the temperature is ranged as $220-230^{\circ} \mathrm{C}$. The explanation is also found in the difference 
between the rheological properties of the melt during filament formation and in the 3D printing. If the variation with the flowing conditions of the fluidity (Figure 2e) and of the melt resistance to flow (Figure $2 \mathrm{~g}$ ) are analyzed, it can be observed that, the optimum temperatures for shaping as filament and for 3D printing are different.

At $200^{\circ} \mathrm{C}$, the temperature at which the shaping as filaments could be done in good conditions, the fluidity of dry PLA is between $1 \mathrm{~g} / 10 \mathrm{~min}$. and $10 \mathrm{~g} / 10 \mathrm{~min}$. and the melt resistance to flow has values ranged as $1600 \mathrm{~Pa}^{*} \mathrm{~s}-1200 \mathrm{~Pa}^{*} \mathrm{~s}$.

At $230^{\circ} \mathrm{C}$, the optimal temperature for 3D printing, the fluidity has values from the range of $22 \mathrm{~g} /$ 10 min. $-60 \mathrm{~g} / 10 \mathrm{~min}$. and the melt resistance to flow between $400 \mathrm{~Pa}^{*} \mathrm{~s}$ and $410 \mathrm{~Pa}^{*} \mathrm{~s}$. This demonstrates that for 3D printing the polymeric material must have a higher fluidity than in case of its shaping as filament and to oppose a lower resistance to flow. The explanation is obvious if the difference in size between the extruder nozzle used for filament achieving (much larger), and the nozzle of the 3D printer (much smaller) is considered.

It has also been observed that the filament formation requires lower shear rates, achievable at lower temperature (Figure $2 \mathrm{a}$ ) and the 3D printing needs higher shear rates possible at elevate temperature.

\subsection{Identification of melt flow conditions for a high-loaded PLA which ensure good adhesion between the overlapped layers}

In an individual experiment it was tried to identify the temperature and the indexer's load that ensures, for a high loaded PLA grade, the fluidity which allows good adhesion between the layers overlapped at the indexer, in an experiment to simulate the 3D printing. The working conditions were defined by shear stress ranged as $20000 \mathrm{~Pa}-90000 \mathrm{~Pa}$ and shear rate between $27.46 \mathrm{~s}^{-1}$ and $412.6 \mathrm{~s}^{-1}$. Figure 7 shows that the overlapping of successive layers, with good adhesion between them was possible only in the following two situations:

1. $\mathrm{T}=185^{\circ} \mathrm{C} ; \mathrm{MFI}=35 \mathrm{~g} / 10 \mathrm{~min}$; $\eta=625 \mathrm{~Pa}^{*} \mathrm{~s}$; medium shear rate of $58,72 \mathrm{~s}-1$

2. $\mathrm{T}=195^{\circ} \mathrm{C} ; \mathrm{MFI}=20 \mathrm{~g} / 10 \mathrm{~min}$.; $\eta=372 \mathrm{~Pa}^{*} \mathrm{~s}$; low shear rate of $52,66 \mathrm{~s}-1$

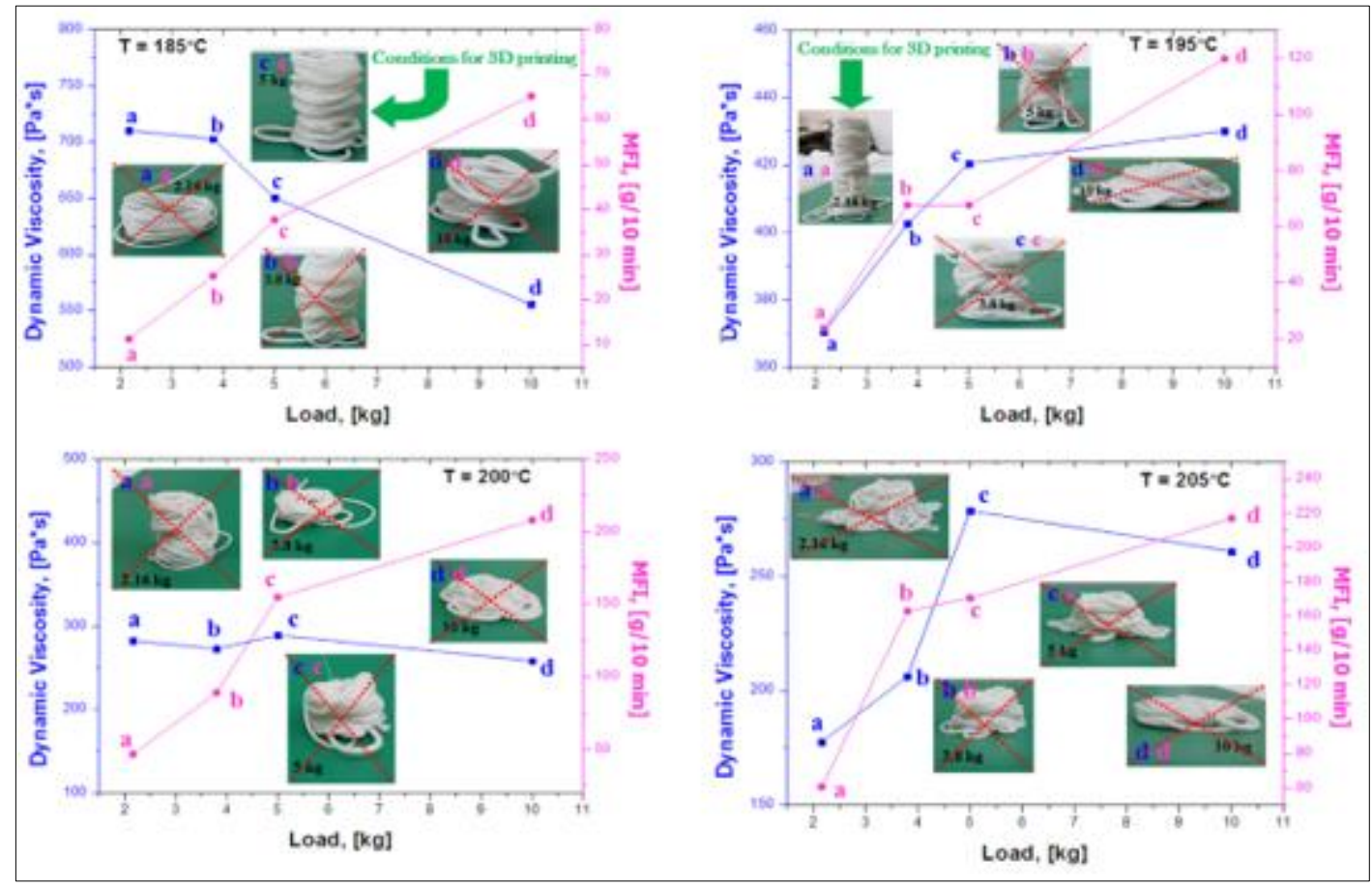

Figure 7. The variation with the flow conditions of the rheological properties of the melted highly loaded PLA and the ilustration of its behavior at overlaying of successive layer 
The found conditions were used with good results both for the blend shaping as filament and for 3D printing (Figure 8). The achieved results show that by using the MFIM it was possible to get filaments with diameter and ovality in accordance with the requirements in the field and the obtained filaments had a good behavior at 3D printing.

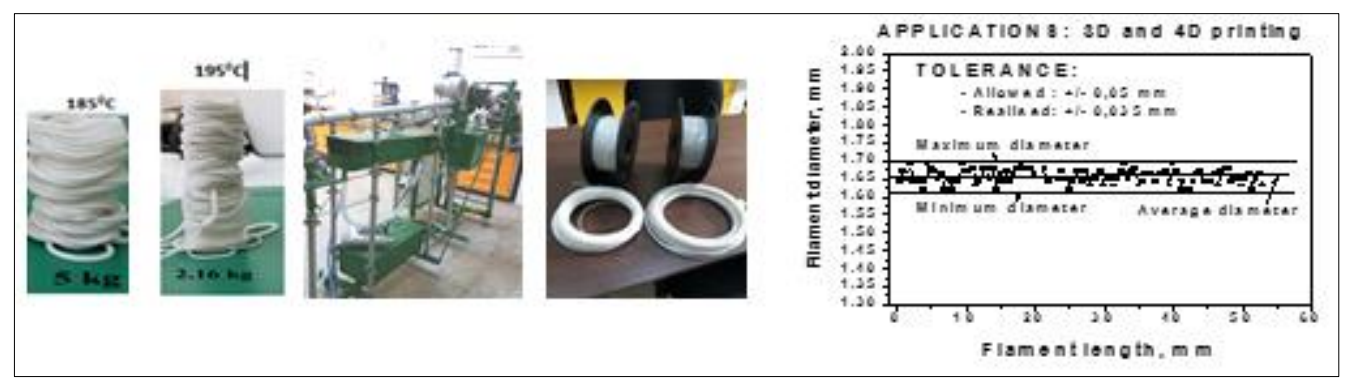

Figure 8. The using of the selected at indexer working conditions (a) for shaping experiment $(b, c)$ and the constancy of the diameter of the obtained filament (d)

\section{Conclusions}

1. The study of the flow properties of melted PLA and/or melted PLA-based materials by the melt flow index method (MFOM) is a useful tool for controlling their shapeability as filaments and the 3D/4D printability since useful information can be obtained on the following topics:

- Selection the optimal molecular weight which allows the melt processing into items by printing technologies. Based on the correlation between viscosity, melt fluidity and molecular weight, the qualitative order of the increasing of the molecular weight for various PLAs grade melt processable into finished products by different techniques was identified as being:

$\mathrm{M}_{\mathrm{w}} 3 \mathrm{D}$ printing $<\mathrm{M}_{\mathrm{w}}$ blow film extrusion $<\mathrm{M}_{\mathrm{w}}$ injection $<\mathrm{M}_{\mathrm{w}}$ thermoforming

- The estimation of the efficiency of the drying, procedure obligatory to be applied prior to the PLA and/or PLA based materials shaping as filaments and to the subsequent 3D/4D printing.

- The estimation of the conditions both for the shaping of PLA or of PLA based material as filaments and for the 3D/4D printing using the obtained filaments.

- Flow conditions that can generate optimal adhesion between the overlapped layers at indexer in an experiment to simulate the $3 \mathrm{D} / 4 \mathrm{D}$ printing

2. The results regarding the use of the flow index method in the preliminary selection of the melt processing conditions for the 3D/4D printing of PLA were verified with good results on a high loaded PLA grade prepared according to an own formulation.

3. The use of the flow index method in preliminary selection of the 3D/4D printing conditions of PLA and of new materials base on PLA is efficient, reproducible and can be extended to other renewable polymers.

Acknowledgments: This work was supported by grants of the Romanian Ministry of Research and Innovation, CCCDI - UEFISCDI, project number nos.23 N/2019, 34 N/2017, PCCE 40-2018 (project 5/3D-LONG LIFE). The authors also thank to their colleagues involved in laboratory work and in the experimental data processing.

\section{References}

1.MURARIU,A., KRAUS, S., Buletion standardizarii, Organismul National de Standardizare, 2016 2.REN,K., Stereolithography: Three Decades of UV Technology Innovation, DSm Funct. Mater. 1, 2015.

3.BÁRTOLO,P.J., Stereolithography - Materials, Processesang, Applications, New York: Springer, 2011, ISBN 978-0-387-92903-3 
4.HARPER, M., LI, G., A review of stimuli-responsive shape memory polymer composites, Polym., 54(9), 2013, 2199-2221, http://doi.org/10.1016/j.polymer.2013.02.023

5.LU, H., HUANG, W.-M., LEN, J., On the origin of Gaussian network theory in the thermo/chemoresponsive shape memory effect of amorphous polymers undergoing photo-elastic transition, Smart Mater. Struct., 25(6), 2016, 065004, http://.doi.org/10.1088/0964-1726/25/6/065004.

6.FENG, X.Q., ZHANG, G.Z., BAI, Q.M, JIANG H.Y, XU, B., LI, H.J., High Strength Self-Healing Magnetic Elastomers With Shape Memory Effect, Macromol. Mater. and Eng., 301(2),2015, 125-132 http://doi.org/10.1002/mame.201500226

7.LU, H., HUANG, W.M., YONG T.Y., Review of chemo-responsive shape change/memory polymers. Pigment \& Resin Technol., 42(4), 2013, 237-246(10), http://doi.org/10.1108/PRT-11-2012-0079

8.WU, X., HUANG, W.M., ZHAO, Y., DING, Z., TANG, C., ZHANG, J., Mechanisms of the Shape Memory Effect in Polymeric Materials, Polym., 5(4), 2013, 1169-1202

https://doi.org/10.3390/polym5041169

9.XIAO, R., CHENG, Z., HUANG, W.M., Programming of Shape-Memory Polymers, Shape-Memory Polymer Device Design book

10.BEHL, M., YASAR RAZZAQ, M., LENDLEIN, A., Multifunctional shape-memory polymers. $A d v$. Mater, 22(31), 2010, 3388-3410, http://doi.org/10.1002/adma.200904447

11.BEHL, M., ZOTZMANN, J., LENDLEIN, A.,Shape-Memory Polymers and Shape-Changing Polymers. Shape-Memory Polymers, 226, 2009, 1-40, https://doi.org/10.1007/12_2009_26

12.HABAULT, D., ZHANG, H., ZHAO, Y., Light-triggered self-healing and shape-memory polymers, Chem. Soc. Rev., 42(17), 2013, 7244-7256, http://doi.org/10.1039/C3CS35489J

13.SKYLAR, T., 4D Printing: Multi-Material Shape Change, Arch. Des., 84(1), 2014, 116-121 https://doi.org/10.1002/ad.1710

14.SADASIVUNI, K.K., DESHMUKH, K., ALMAADEED, M.A., 3D and 4D Printing of Polymer Nanocomposite Materials, Processes, Applications, and Challenges, 2019, ISBN 978-0-1281730-2-2.

15.SUBASHA, A., KANDASUBRAMANIAN, B., 4D printing of shape memory polymers, Europ. Polym. J., 134(5), 2020, 109771, http://doi.org/10.1016/j.eurpolymj.2020.109771

16.STROBL, G.R., The Physics of Polymers Concepts for Understanding Their Structures and Behavior, Springer-Verlag, 1996, ISBN 3-540-60768-4

17.***Understanding Melt Index and ASTM D1238, Journal of Testing and Evaluation, Journal of Testing and Evaluation, 41(1), 2013, 50-62.

18.DIMONIE, D., COSEREA, R.M., SINFUREL, G., ZAHARIA, C., DARIE, R.N., POP, S.F., Rheological Properties of PolyvinylChloride - Thermoplastic Polyurethane Blends. Mater. Plast., 46(3), 2009, 321-326

19.DIMONIE, D., PETRACHE, M., DAMIAN, C., ANTON, L., MUSAT, M., DIMA, S.O., JINESCU, C. and RAPA M., New Evidences on the Process Sensitivity of Some Renewable Blends Based on Starch considering Their Melt Rheological Properties, Interna J. of Polym. Sci., 10, 2016 http://doi.org/10.1155/2016/7873120

20.SHOJAEIARANI,J., BAJWA, D.S., REHOVSKY, C., BAJWA, S., VAHIDI, G., Deterioration in the Physico-Mechanical and Thermal Properties of Biopolymers Due to Reprocessing, Polym., 11(1), 2019, 58, https://doi.org/10.3390/polym11010058

21.Whelan A., Polymer Technology Dictionary, Springer Netherlands, 1994, ISBN 978-94-011-1292-5 22.VLACHOPOULOS, J., POLYCHRONOPOULOS, N.P., Chapter 1basic concepts in polymermelt rheology and theirimportance in processing. Applied Polymer Rheology: Polymeric Fluids with Industrial Applications, 2012, ISBN 978-0-9952407-2-8.

23.DIMONIE, D., MUSAT, M., DONCEA, S.M., DAMIAN, C.M., Controlling the Melt Resistance to Flow as a Possibility of Improving the Miscibility and the Time Behavior of Some Blends Based on Starch, International J. of Polym. Sci., 12, 2015, http://doi.org/10.1155/2015/582901 24.***American Society for Testing and Materials "ASTM F42 group" - Additive Manufacturing" 
25.LAI, S.M., WU, W.-L., WANG, Y.-J., Annealing effect on the shape memory properties of polylactic acid (PLA)/thermoplastic polyurethane (TPU) bio-based blends, J. of Polym. Research, 23, 2016, 99 http://doi.org/10.1007/s10965-016-0993-6

26.DOGAN,S.K., BOYACIOGLU, S., KODAL, M., GOKCE, O., Thermally induced shape memory behavior, enzymatic degradation and biocompatibility of PLA/TPU blends: "Effects of

compatibilization", J. of the Mech. Behav. of Biomed. Mater., 71, 2017, 349-361.

http://doi.org/10.1016/j.jmbbm.2017.04.001

27.SONG, S.J., CHANG,K.J., NAGUIB, H.E., Biocompatible shape memory polymer actuators with high force capabilities, European Polym. J., 67, 2015, 186-198

http://doi.org/10.1016/j.eurpolymj.2015.03.067

28.QU, Z., YIN, D., ZHOU, H., WANG, X., ZHAO, S., Cellular morphology evolution in nanocellular poly (lactic acid)/thermoplastic polyurethane blending foams in the presence of supercritical N2. European Polym. J., 116, 291-301, 2019, http://doi.org/10.1016/j.eurpolymj.2019.03.046

29.MI, H.-Y., SALICK, M.R., JING, X., JACQUES, B.R., CRONE, W.C., PENG, X.-F., TURNG, L.S.,Characterization of thermoplastic polyurethane/polylactic acid (TPU/PLA) tissue engineering scaffolds fabricated by microcellular injection molding,

30. SONG, J.J, CHANG, NAGUIB, H.E., Design and characterization of biocompatible shape memory polymer (SMP) blend foams with a dynamic porous structure. Polym., 56(15), 2015, 82-92

http://doi.org/10.1016/j.polymer.2014.09.062

31.JING, X., MI, H.-Y., SALICK, M.R., CORDIE, T., CRONE, W.C., PENG, X.-F., TURNG, L.-S., Morphology, mechanical properties, and shape memory effects of poly(lactic acid)/ thermoplastic polyurethane blend scaffolds prepared by thermally induced phase separation, J. of Cell Plast., $\mathbf{0}(0)$, 2014, 1-19, http://doi.org/10.1177/0021955X14525959

32.DIMONIE D.O.A, GRIGORE, M.E., CONSTANTIN, V., DONCEA, S.M., STOICA, R., GRIGORESCU, R.M., 2018, No. A/01063/08.12.2017.

33.TOOLEY M., Design Engineering Manual, Butterworth-Heinemann, 2009,

ISBN 978-1-85617-838-9.

34.SADIKU-AGBOOLA, O., SADIKU, R., ADEGBOLA, A.,BIOTIDARA, O., Rheological Properties of Polymers: Structure and Morphology of Molten Polymer Blends. Mater. Sci. and Appl., 2(1), 2011, 30-41, http://doi.org/10.4236/msa.2011.21005

35.BARNES A. HOWARD, A handbook of elementary rheology, University of Wales Institute of NonNewtonian Fluid Mechanics,2000, ISBN 0-9538032-0-1.

36.BREMNER, T., COOK, D.G., RUDIN, A., Further comments on the relations between melt flow index values and molecular weight distributions of commercial plastics, J. of Appl. Polym. Sci., 43(1773), 1991

http://doi.org/10.1002/app.1991.070430920

37.ELSAWY, M.A., KIM, K.-H., DEEP, A., Hydrolytic degradation of polylactic acid (PLA) and its compositesno, Renew. Sustain. Energy Rev.,79, 2017, 1346-1352

http://doi.org/10.1016/j.rser.2017.05.143

38.SIMMONS, H., KONTOPOULOU, M., Hydrolytic degradation of branched PLA produced by reactive extrusion, Polym. Degrad. Stab., 158, 2018, 228-237,

http://doi.org/10.1016/j.polymdegradstab.2018.11.006

39.FREDDYS, B.G., LORENZO, V., DE LA ORDEN, M.U., URREAGA, J.M., Effect of different mechanical recycling processes on the hydrolytic degradation of poly(1-lactic acid). Polym. Degrad. Stab., 113, 2016, 339-348

http://doi.org/10.1016/j.polymdegradstab.2016.09.018

40.***Plastemart.com. (n.d.). Trade Leads from Global Plastics Industry. (Plastemart.com) Retrieved September 3, 2020, http://www.plastemart.com/

Manuscript received: 3.09 .2020 